\title{
Effect of reaction on the tensile behavior of infiltrated boron carbide- aluminum composites
}

\author{
Marianna Kouzeli ${ }^{\mathrm{a}, \mathrm{b}}$, Christopher San Marchi ${ }^{\mathrm{a}, \mathrm{b}}$, Andreas Mortensen ${ }^{\mathrm{a}, *}$ \\ a Laboratory for Mechanical Metallurgy, Ecole Polytechnique Fédérale de Lausanne, CH-1015 Lausanne, Switzerland \\ ${ }^{\mathrm{b}}$ Department of Materials Science and Engineering, Northwestern University, Evanston, IL 60208-3108, USA
}

Received 4 September 2001; received in revised form 10 January 2002

\begin{abstract}
Gas pressure assisted liquid metal infiltration was employed in the fabrication of various high volume fraction $\mathrm{B}_{4} \mathrm{C}-\mathrm{Al}$ composites. Two reaction products were observed and identified in the composites, namely $\mathrm{AlB}_{2}$ and $\mathrm{Al}_{3} \mathrm{BC}$. $\mathrm{An}_{\text {increase in total }}$ volume fraction of these phases results in an increase in flow stress of the composites, concomitant to a decrease in ductility. The latter was shown to be related to an accelerated accumulation of damage, which we quantified by monitoring the stiffness of the composites as a function of strain. A simple relationship is used to quantitatively link internal damage accumulation and tensile ductility in the present composites. (C) 2002 Elsevier Science B.V. All rights reserved.
\end{abstract}

Keywords: Boron carbide; Aluminum; Metal matrix composite; Damage in composites; Tensile ductility

\section{Introduction}

An important issue in the production of metal matrix composites is the chemical compatibility between the matrix and the reinforcement, particularly when using liquid metal processes such as infiltration. There are numerous examples in the literature of promising material combinations that exhibit poor mechanical properties due to chemical incompatibility [1-3]. In the $\mathrm{B}_{4} \mathrm{C}-\mathrm{Al}$ system chemical compatibility is of particular interest, since this system has received significant industrial investment for high-strength applications $[4,5]$.

The interface chemistry of the $\mathrm{B}_{4} \mathrm{C}-\mathrm{Al}$ couple has been addressed in several studies [6-10]. Boron carbide and aluminum react at temperatures greater than $700{ }^{\circ} \mathrm{C}$ producing $\mathrm{AlB}_{2}$ and an aluminum borocarbide, $\mathrm{Al}_{3} \mathrm{BC}$, which has only recently been identified $[9,11]$. Other more complicated phases develop at temperatures greater than $900{ }^{\circ} \mathrm{C}$; however, such temperatures can easily be avoided in processing since the melting point of

\footnotetext{
* Corresponding author. Tel.: +41-21-693-2912; fax: +41-21-6934664

E-mail address: andreas.mortensen@epfl.ch (A. Mortensen).
}

aluminum is $660{ }^{\circ} \mathrm{C}$. The decomposition mechanisms of boron carbide in liquid aluminum between 700 and $900{ }^{\circ} \mathrm{C}$ have been summarized by Viala et al. [9]. Dissolution of the carbide rapidly saturates the melt with boron and carbon since the maximum solubility of these two elements in aluminum is relatively low $(0.1$ wt. $\%$ and a few tenths of a ppm, respectively, at 1000 $\mathrm{K})$. Subsequently, $\mathrm{AlB}_{2}$ nucleates on impurity seeds from the supersaturated melt, while the $\mathrm{Al}_{3} \mathrm{BC}$ phase nucleates at the $\mathrm{B}_{4} \mathrm{C}$ surface. Growth continues via a classical dissolution-precipitation mechanism [9].

Studies on the mechanical properties of $\mathrm{B}_{4} \mathrm{C}-\mathrm{Al}$ composites can also be found in the literature; however, findings regarding the chemical compatibility of the $\mathrm{B}_{4} \mathrm{C}-\mathrm{Al}$ couple and its effects on the mechanical behavior of these materials are not consistent. Nayeb Hashemi et al. [12] studied damage accumulation in two different aluminum alloys (2219 and 6061) reinforced with 20 vol.\% $\quad \mathrm{B}_{4} \mathrm{C}$ particles subjected to elevated $\left(535{ }^{\circ} \mathrm{C}\right)$ temperatures. They found that increasing exposure to high temperature degraded the interface strength of the composite and thus changed the predominant damage mode from particle fracture to interface decohesion. Stephens and co-workers [13] also report a weak interface due to reaction in a $\mathrm{B}_{4} \mathrm{C}$ reinforced $\mathrm{Al}-7 \mathrm{Si}$ alloy produced by stir-casting; the 
interface was found to be responsible for the poor mechanical performance of those composites. Vaidya et al. [14] on the other hand, provide evidence that in spray-cast 15 vol. $\% \mathrm{~B}_{4} \mathrm{C}$ reinforced 6061 aluminum alloy, the reinforcement significantly enhances the mechanical properties of the matrix both in quasi-static and dynamic testing. The composites are found to be reaction-free and the interface is reported to be very strong due to good wetting of the $\mathrm{B}_{4} \mathrm{C}$ particles. Nieh and Karlak [15] report inertness of $\mathrm{B}_{4} \mathrm{C}$ in aluminum in a study of aging kinetics of a 6061 aluminum-23 vol.\% $\mathrm{B}_{4} \mathrm{C}$ composite prepared by powder metallurgy. Infiltrated $\mathrm{B}_{4} \mathrm{C}-\mathrm{Al}$ cermets were characterized in high strain rate compression by several authors [16-18] but these authors do not comment on reaction.

The effect of reaction (at $T>1100{ }^{\circ} \mathrm{C}$ ) on the mechanical properties of high volume fraction ( $>$ $70 \%) \mathrm{B}_{4} \mathrm{C}$ reinforced aluminum composites was studied by Pyzik and Beaman [4]. They find that the Young's modulus and flexural strength increase as the extent of reaction increases, accompanied by a decrease in fracture toughness. The changes in mechanical properties, they conclude, are a result of an increase in ceramic phase contiguity and of depletion of the metallic phase due to reaction. While the same authors mention microstructural damage in the form of cracks in large reaction phases, no quantification of this damage was reported. It would therefore be of interest to quantify microstructural damage and its influence on the mechanical properties of $\mathrm{B}_{4} \mathrm{C}-\mathrm{Al}$ composites, particularly since damage accumulation in such particle reinforced composites has been shown to exert a strong influence on their mechanical behavior, especially their ductility (e.g. [19-23]). We present in what follows a study of the extent of reaction and its influence on the microstructure, tensile properties and damage accumulation for several $\mathrm{B}_{4} \mathrm{C}-\mathrm{Al}$ composites produced by infiltration, varying the average size of the reinforcement and the reaction time between liquid $\mathrm{Al}$ and $\mathrm{B}_{4} \mathrm{C}$ at $750{ }^{\circ} \mathrm{C}$.

\section{Experimental procedures}

\subsection{Processing and materials}

$\mathrm{B}_{4} \mathrm{C}$-particle reinforced high-purity $(99.99 \%)$ aluminum composites containing close to 50 vol. $\%$ ceramic were produced by gas pressure assisted liquid metal infiltration. High-purity aluminum was used to avoid complications due to the presence of alloying elements, both in terms of second phases in the matrix and additional reaction pathways. The composite microstructure was varied by using several commercial grades (FEPA-specified size distributions) of $\mathrm{B}_{4} \mathrm{C}$ powders manufactured by Elektroschmelzwerk Kempten $\mathrm{GmbH}$ (Kempten, Germany) and by controlling the amount of reaction between the reinforcement and the matrix during processing as specified below.

The tap densities (i.e. the density to which the powders pack under gravity, assisted by tapping) of the different $\mathrm{B}_{4} \mathrm{C}$ powders were measured in graduated cylinders with approximately the same inner diameter as the crucibles used for preparation of the composites, and are given in Table 1 as a volume percentage. These values are the theoretical concentrations of $\mathrm{B}_{4} \mathrm{C}$ in the composites in the limit of no reaction between the matrix and the particles. Consistency between the measured tap density and the actual volume fraction of reinforcement in the composite (for particles of the same average size and size distribution) was confirmed using the non-reactive $\mathrm{Al}_{2} \mathrm{O}_{3}-\mathrm{Al}$ system.

Preforms of loose powder were prepared in high purity (99.8\%) alumina crucibles by tapping the crucible until the density of the powder reached a stable value (the tap density for the specific powder). After packing the powder a thin layer of alumina fiber felt was placed on top of the preform followed by a billet of aluminum. The alumina acts as a temporary physical barrier between the boron carbide and the aluminum prior to infiltration. This assembly was then suspended in a pressure vessel designed for gas-pressurization. In this apparatus, the crucible is held in the hot zone of the vessel by a long rod such that the position of the crucible can be adjusted by positioning of this rod. After placement of the crucible assembly, the infiltration chamber was sealed, evacuated to $2 \mathrm{~Pa}$ residual pressure, and subsequently heated to $750{ }^{\circ} \mathrm{C}$. Once the temperature had stabilized, argon was introduced at a pressure of $8 \mathrm{MPa}$. Subsequent to infiltration, the composite was directionally solidified by lowering the crucible onto a copper chill at the bottom of the infiltration machine.

The microstructures of these composites can be modified by controlling the time between infiltration and solidification, which we call the interaction time. Material with minimized interaction time, about $2 \mathrm{~min}$ for this experimental set-up, is called type B material. Type $\mathrm{R}$ material, in comparison, experiences an interaction time of about 15 min (Table 1). In what follows, the composites are specified by their average reinforcement size in micrometers, followed by the letter B or R referring to nominally unreacted or reacted composites respectively.

\subsection{Composite characterization}

Sections of all the composites were polished and examined under an optical microscope and a scanning electron microscope. Classical X-ray diffraction techniques and transmission electron microscopy (TEM) diffraction patterns were used to identify the reaction phases. The concentration of the different constituents was determined by density measurements and image 
Table 1

Composite characteristics

\begin{tabular}{lllll}
\hline $\begin{array}{l}\text { Composite } \\
\text { designation }\end{array}$ & $\begin{array}{l}\text { Particle } \\
\text { specification }^{\mathrm{a}}\end{array}$ & $\begin{array}{l}\text { Average particle size } \\
(\mu \mathrm{m})^{\mathrm{b}}\end{array}$ & $\begin{array}{l}\text { Theoretical concentration } \\
\mathrm{B}_{4} \mathrm{C}(\mathrm{vol} . \% \pm 0.5)\end{array}$ & $\begin{array}{l}\text { Theoretical density } \\
\left(\mathrm{g} / \mathrm{cm}^{3} \pm 0.005\right)\end{array}$ \\
\hline 82B/R & F150 & 82 & 52 & 2.597 \\
58B/R & F220 & 58 & 53 & 2.587 \\
29B/R & F320 & 29 & 57 & 2.616 \\
\hline
\end{tabular}

a Manufacturer classifications.

b FEPA (Federation of European Producers of Abrasives) standard 42-1984 R 1993.

analysis. The composite density was measured using a high-precision microbalance and an immersion technique based on Archimedes' principle.

A dog-bone geometry was used for tensile testing according to ASTM standard B557M-84. The tensile samples were machined from the composite castings using electro-discharge machining. Tensile tests were conducted on a screw-driven universal-testing machine at a nominal strain rate of $10^{-4} \mathrm{~s}^{-1}$. The initial Young's modulus of the composites, $E_{0}$, was determined during several unload-reload cycles after a small increment in plastic deformation, $<0.2 \%$ [24]. In addition to standard monotonic tensile testing, unload-reload cycles were repeated at predetermined strain increments to enable the monitoring of damage accumulation, as measured from the decrease in stiffness with strain [24]. From these measurements, the damage parameter $D_{\mathrm{E}}$ was calculated as

$D_{\mathrm{E}}=1-\frac{E}{E_{0}}$

where $E$ is the Young's modulus as a function of strain.

Tensile specimens that were loaded to failure were sectioned parallel to the loading axis, mechanically polished and finally electropolished $(5 \mathrm{~s}$ at $50 \mathrm{~V}$ with Struers, Rødovre Denmark, A2 electrolyte). This electropolishing step is important for the identification of damage micromechanisms in the composites since it removes the smeared aluminum layer introduced by mechanical polishing $(\sim 10 \mu \mathrm{m})$, thus revealing any voids within the matrix. It also allows for the distinction between superficial particle cracks caused by mechanical polishing, and cracks running through particles that originate from particle failure during tensile straining.

\section{Results}

\subsection{Microstructural characterization and density measurements}

All as-cast composite microstructures feature a homogeneous distribution of $\mathrm{B}_{4} \mathrm{C}$ in a pore-free aluminum matrix. Optical metallography revealed a reaction phase that appears yellow, in contrast to the gray $\mathrm{B}_{4} \mathrm{C}$ particles. This yellow phase was present in all the composites, both type B and type R. It was identified by its TEM diffraction patterns as $\mathrm{AlB}_{2}$, consistent with several other studies $[4,8,9]$. This $\mathrm{AlB}_{2}$ phase was found to nucleate (and grow) primarily on impurity $\mathrm{TiB}_{2}$ particles existing in the starting powder (Fig. 1).

No other reaction products were found by optical metallography on the polished sections of the type B composites. Small hexagonal crystals, however, were occasionally observed by scanning electron microscopy on the fracture surfaces of unreacted composites (Fig. 2). These hexagons grow on $\mathrm{B}_{4} \mathrm{C}$ particles and seem to be nuclei of a second reaction product, namely $\mathrm{Al}_{3} \mathrm{BC}$, which is visible under the optical microscope in materials with longer interaction times, type $\mathrm{R}$ materials. This aluminum borocarbide nucleates and grows at the $\mathrm{B}_{4} \mathrm{C}-$ $\mathrm{Al}$ interface and was identified by $\mathrm{X}$-ray diffraction. These observations confirm the findings of Viala et al. [9]. The $\mathrm{Al}_{3} \mathrm{BC}$ phase appears gray in optical micrographs (Fig. 3), and does not seem to form a continuous layer around the interface, at least for the reaction times explored in this study. The contiguity of the $\mathrm{B}_{4} \mathrm{C}$ particles appears to be enhanced by the increase in volume of reaction products in type $\mathrm{R}$ materials, as both the $\mathrm{AlB}_{2}$ and $\mathrm{Al}_{3} \mathrm{BC}$ phases grow with interaction time to form bridges between adjacent $\mathrm{B}_{4} \mathrm{C}$ particles (Fig. 3).

The extent of reaction in the two groups of composites was determined using precision density measurements. It is evident from Table 2 that the increased

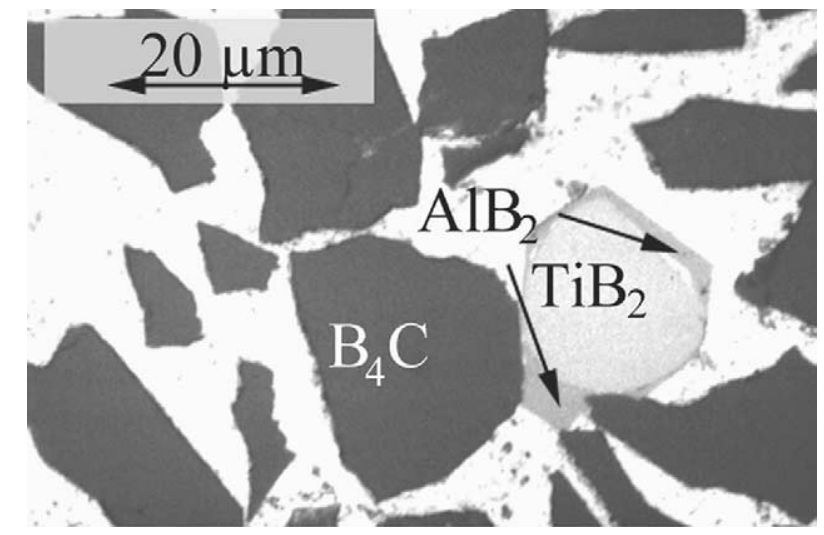

Fig. 1. Optical micrograph of $\mathrm{AlB}_{2}$ in composite 29B growing on a $\mathrm{TiB}_{2}$ impurity (as-cast). 


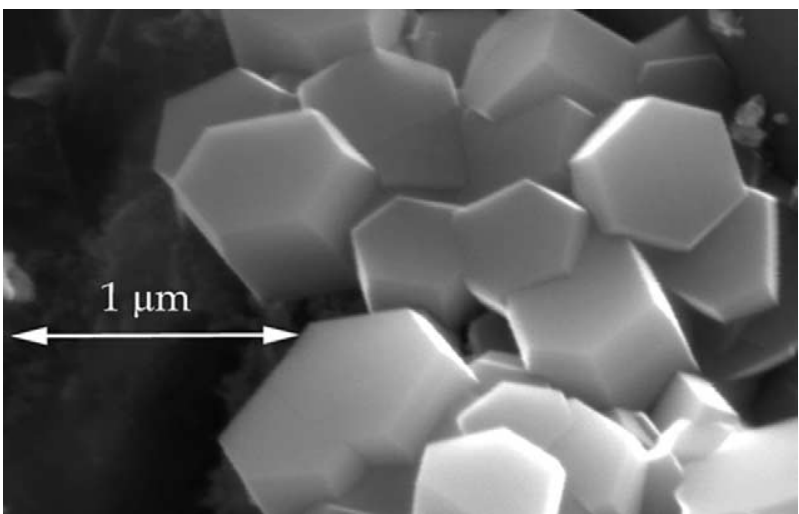

Fig. 2. $\mathrm{Al}_{3} \mathrm{BC}$ as seen by $\mathrm{SEM}$ on the fracture surface of type $\mathrm{B}$ materials.

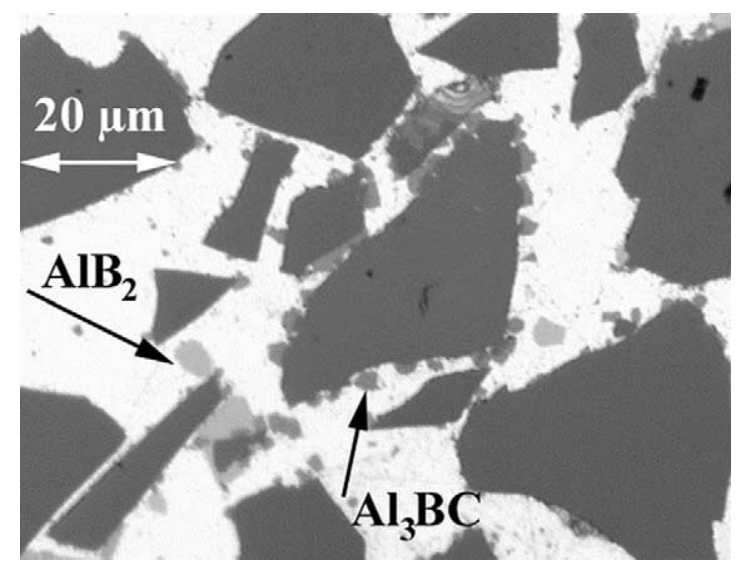

Fig. 3. Optical micrograph of composite 29R (as-cast).

Table 2

Density measurements and concentration of reaction products

\begin{tabular}{lll}
\hline $\begin{array}{l}\text { Composite } \\
\text { designation }\end{array}$ & $\begin{array}{l}\text { Measured density } \\
\left(\mathrm{g} / \mathrm{cm}^{3} \pm 0.0005\right)\end{array}$ & $\begin{array}{l}\text { Concentration of reaction } \\
\text { products }(\mathrm{vol} . \% \pm 0.5)\end{array}$ \\
\hline $82 \mathrm{~B}$ & 2.598 & 0.3 \\
$82 \mathrm{R}$ & 2.602 & 1.2 \\
$58 \mathrm{~B}$ & 2.601 & 1.7 \\
$58 \mathrm{R}$ & 2.611 & 3.3 \\
29B & 2.592 & 1.6 \\
29R & 2.598 & 2.9 \\
\hline
\end{tabular}

interaction time between the liquid $\mathrm{Al}$ and the $\mathrm{B}_{4} \mathrm{C}$ particles during processing results in a higher composite density. This is a consequence of the increased fraction of reaction products and the greater density of these products compared with the composite ingredients: $2.7 \mathrm{~g}$ $\mathrm{cm}^{-3}$ for pure $\mathrm{Al}, 2.5 \mathrm{~g} \mathrm{~cm}^{-3}$ for $\mathrm{B}_{4} \mathrm{C}, 3.19 \mathrm{~g} \mathrm{~cm}^{-3}$ for $\mathrm{AlB}_{2}$ [25], and $2.83 \mathrm{~g} \mathrm{~cm}^{-3}$ for $\mathrm{Al}_{3} \mathrm{BC}$ [9]. The volume fraction of the reaction phases can thus be estimated from the density using a weighted rule of mixtures based on the stoichiometry of the reaction

$9 \mathrm{Al}+2 \mathrm{~B}_{4} \mathrm{C} \rightarrow 3 \mathrm{AlB}_{2}+2 \mathrm{Al}_{3} \mathrm{BC}$ and the initial density of the (non-reacted) composites. Table 2 lists the measured density and the estimated concentration of reaction products for each composite. Image analysis can also be used to determine the concentration of the reaction products; however, polishing artifacts render this method less precise for the present materials than the simple calculated estimate from density measurements. Image analysis nonetheless corroborates the findings in Table 2: the amount of reaction products measured by image analysis is near 2 vol.\% for type B and slightly less than 5 vol.\% for type R materials.

\subsection{Tensile properties}

Table 3 summarizes the tensile properties of the composites measured in this study and typical tensile flow curves are shown in Fig. 4. Note that the volume fraction ceramic quoted in Table 3 is the sum of all three ceramic phases present: $\mathrm{B}_{4} \mathrm{C}, \mathrm{AlB}_{2}$, and $\mathrm{Al}_{3} \mathrm{BC}$. Values of ultimate tensile strength (UTS) and elongation at failure $\left(\varepsilon_{\mathrm{f}}\right)$ are an average of at least three tensile tests. The values of $\varepsilon_{\mathrm{f}}$ are taken as a measure of the ductility of the material, and are computed at the point of tensile instability according to the Considere criterion (Fig. 5), i.e. at the intersection of the stress-strain curve and its derivative

$\frac{\mathrm{d} \sigma}{\mathrm{d} \varepsilon}=\sigma$

(this measure of ductility was adopted because it is independent of the geometry of the tensile samples; in most cases it differs little from the final total elongation of the samples (Fig. 4).

The initial Young's modulus $\left(E_{0}\right)$ of the composites increases predominantly as a function of the volume fraction ceramic (Table 3 and Fig. 6). The tensile flow stress for the respective material types (B and $\mathrm{R}$ ) is a strong function of particle size, increasing as the average particle size decreases (Fig. 4). The same trend can be extended to the measured elongations at failure $\left(\varepsilon_{\mathrm{f}}\right)$ (Table 3). Furthermore, type $\mathrm{R}$ composites exhibit a higher flow stress and a lower elongation to failure than type B composites reinforced with particles of the same size (Fig. 5 and Table 3).

\subsection{Internal damage accumulation}

Metallographic observations reveal that in type B composites damage accumulates predominantly through the fracture of reinforcing $\mathrm{B}_{4} \mathrm{C}$ particles (Fig. 7). Additionally, some matrix cavitation was observed in highly constrained areas of the matrix, i.e. where the interparticle spacing is smaller than average (Fig. 7). No evidence of interfacial failure was found. 
Table 3

Tensile properties of the $\mathrm{B}_{4} \mathrm{C}-\mathrm{Al}$ composites

\begin{tabular}{lllll}
\hline Composite designation & Ceramic concentration (vol.\%) & $E_{0}(\mathrm{GPa} \pm 3)$ & UTS $(\mathrm{MPa} \pm 4)$ & $\varepsilon_{\mathrm{f}}(\mathrm{mm} / \mathrm{mm} \pm 0.004)$ \\
\hline 82B & 52 & 166 & 111 & 0.014 \\
82R & 53 & 165 & 130 & 0.007 \\
58B & 54 & 169 & 132 & 0.026 \\
58R & 55.5 & 178 & 161 & 0.009 \\
29B & 58 & 183 & 201 & 0.028 \\
29R & 59 & 194 & 229 & 0.01 \\
\hline
\end{tabular}

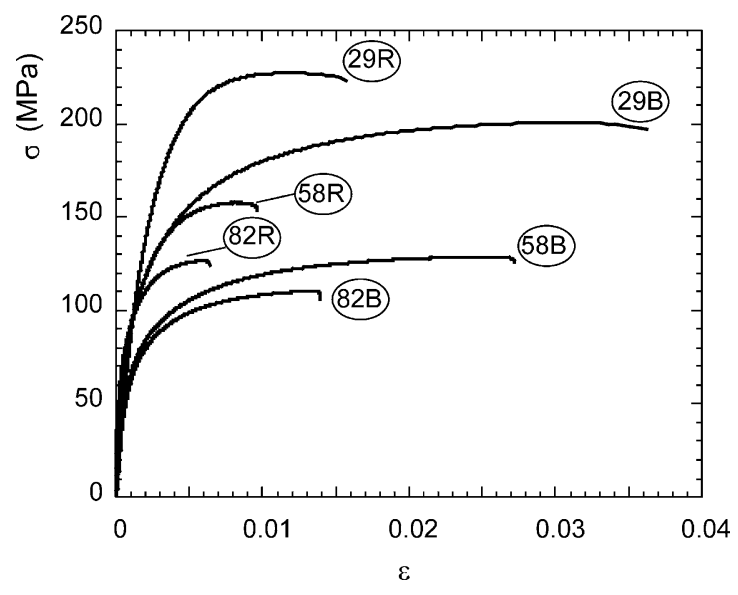

Fig. 4. Typical flow curves of the $\mathrm{B}_{4} \mathrm{C}-\mathrm{Al}$ composites.

The extent of particle fracture was observed and measured to be a function of particle size; measurements of the fraction of broken particles were made in the gauge length of failed tensile specimens, far enough from the fracture surface $(\sim 3 \mathrm{~mm})$ to avoid localized deformation effects prior to failure. In composite $58 \mathrm{~B}$, $32 \%$ of the reinforcing particles were broken at a fracture strain of $2.6 \%$, while in composite $29 \mathrm{~B}$ only $22 \%$ of the particles were broken at a slightly larger fracture strain of $2.8 \%$. The decrease of Young's modulus as a function of plastic strain is a measure of damage that is highly sensitive to particle fracture [26$28]$ and supports the quantitative metallographic findings: composite $58 \mathrm{~B}$, for example, suffers from a greater loss in stiffness than composite 29B at all strains (Fig. 8).

These same trends can be extended to the type $\mathrm{R}$ materials. No change in damage mechanisms was observed; however, it is clear from Fig. 8 that the rate of damage accumulation is much higher for type $\mathrm{R}$ composites in comparison to type B composites. The fraction of broken particles in the gauge length far from the fracture surface was measured for composites with $29 \mu \mathrm{m}$ diameter reinforcements, and found to be almost equivalent for both types of material: $23 \%$ broken particles in $29 \mathrm{R}$ compared with $22 \%$ for the $29 \mathrm{~B}$ material. This damage, however, accumulates at significantly different rates for the two types of material since the fracture strains are $1 \%$ for $29 \mathrm{R}$ compared to $2.8 \%$ for $29 \mathrm{~B}$.

\section{Discussion}

\subsection{Young's modulus}

During processing of $\mathrm{B}_{4} \mathrm{C}-\mathrm{Al}$ composites by liquid metal infiltration, boron carbide reacts with the liquid aluminum. The reaction products for the processing temperature employed in the present study (and in general for temperatures below $870{ }^{\circ} \mathrm{C}$ [9]) are the ternary carbide $\mathrm{Al}_{3} \mathrm{BC}$ and the diboride $\mathrm{AlB}_{2}$. The volume of these reaction phases depends on the time between infiltration and solidification; for long interaction times, the net volume of ceramic phases increases at the expense of the metallic phase in the composites, Eq. (2). This effective increase in the volume fraction of the stiffer ceramic phase results in an increase of the Young's modulus of type $\mathrm{R}$ composites as compared to type B (Table 3).

Experimental results for the Young's modulus of the present composites are compared in Fig. 6 with values predicted by a three-phase self-consistent model for $\mathrm{B}_{4} \mathrm{C}$ particle reinforced aluminum composites (lower, dashed, line) [29]. It is assumed in the calculation that the matrix is pure aluminum $(99.99 \%)$ and that all of the ceramic phases present in the composites have properties identical to $\mathrm{B}_{4} \mathrm{C}$. For comparison, predictions of the same model for aluminum particles in boron carbide are also given in Fig. 6 (top dotted line). As seen, all composites of the present work remain close to the predictions of the model for isolated carbide particles in a matrix of aluminium. The only positive deviation noted is for composite $29 \mathrm{R}$, which features the highest fraction ceramic: this deviation is slight in comparison with the width of the band between the two predictions. The level of interconnectivity created by the reaction phases in the present composites is thus apparently not sufficient to significantly affect load partition between the matrix and the reinforcement during elastic deformation. 
(a)

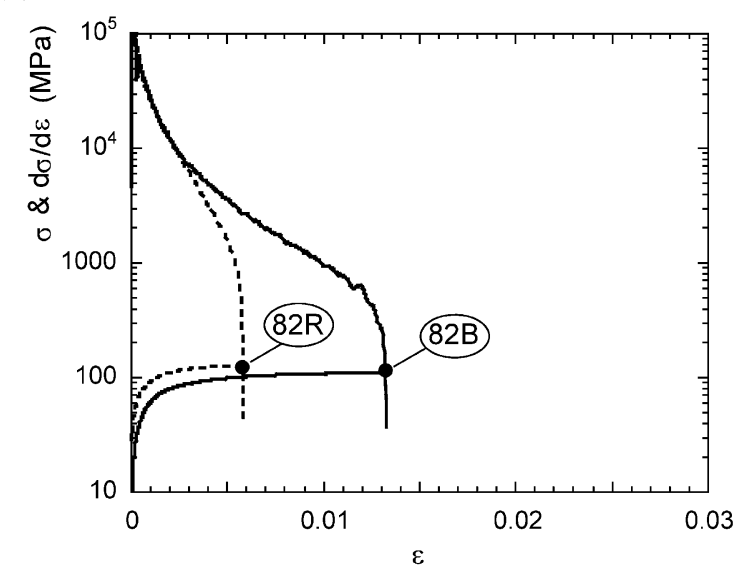

(b)

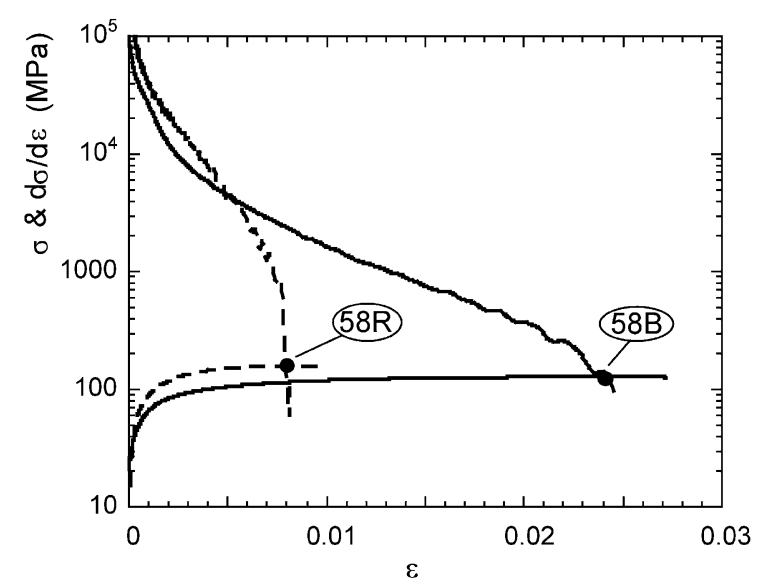

(c)

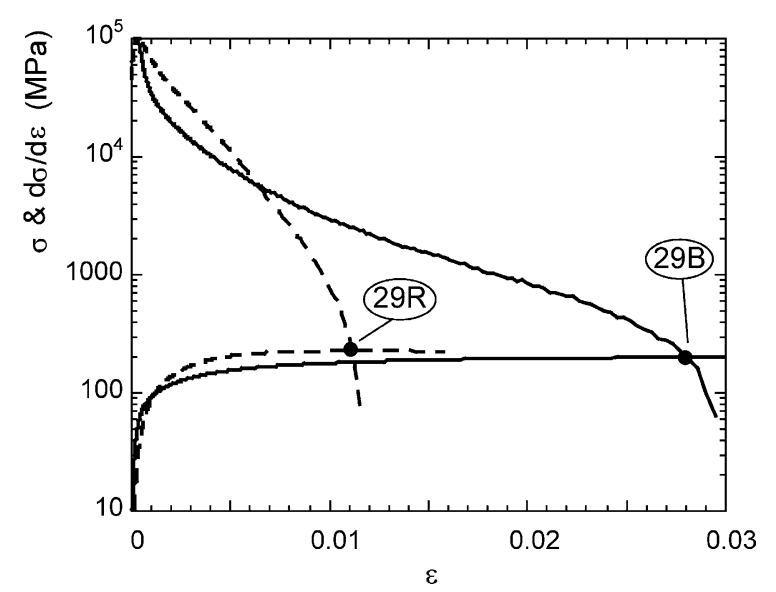

Fig. 5. Flow curves and rate of strain hardening for composites (a) $82 \mathrm{~B}$ and $82 \mathrm{R}$, (b) $58 \mathrm{~B}$ and $58 \mathrm{R}$, and (c) $29 \mathrm{~B}$ and $29 \mathrm{R}$.

\subsection{Flow stress}

In both type $\mathrm{B}$ and type $\mathrm{R}$ materials, the tensile flow curve is dependent on the size of the reinforcement: in each group of composites the tensile stress at all strains

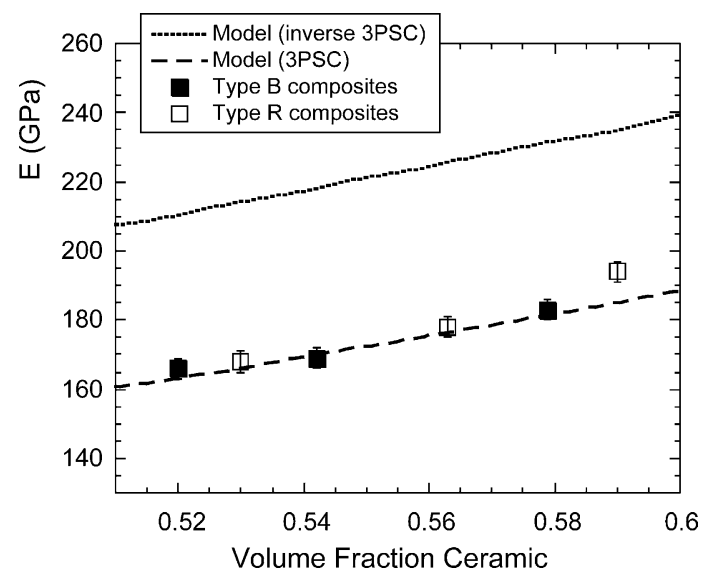

Fig. 6. Young's modulus as a function of volume fraction ceramic: experimental data (square symbols), three-phase self-consistent model for a composite of spherical boron carbide particles in aluminum (lower, dashed line) and same model for aluminum particles in boron carbide (top, dotted line).
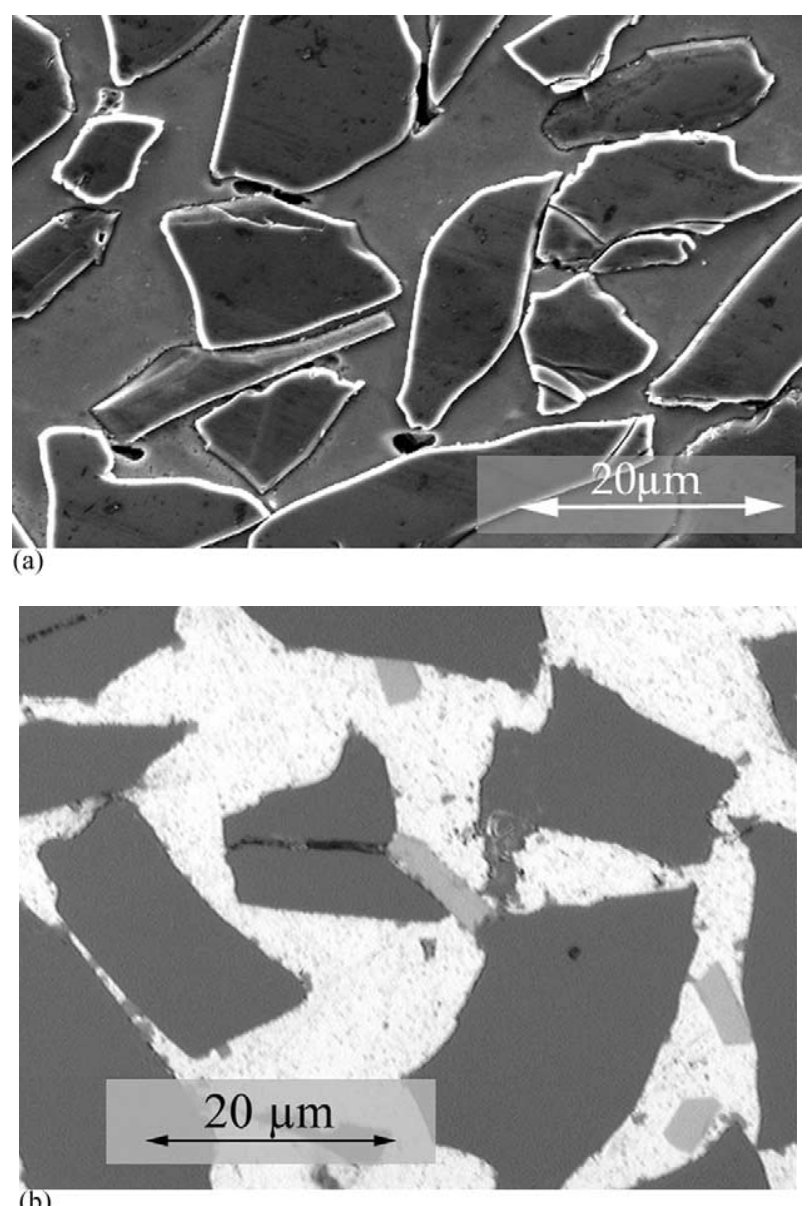

(b)

Fig. 7. (a) Scanning electron micrograph of composite $29 \mathrm{~B}$ and (b) optical micrograph of composite $29 \mathrm{R}$ showing the active damage micromechanisms during tensile straining. Tensile axis is perpendicular to the scaling bar.

is greater for materials with smaller reinforcements (Table 3). The influence of smaller reinforcing particles 
(a)

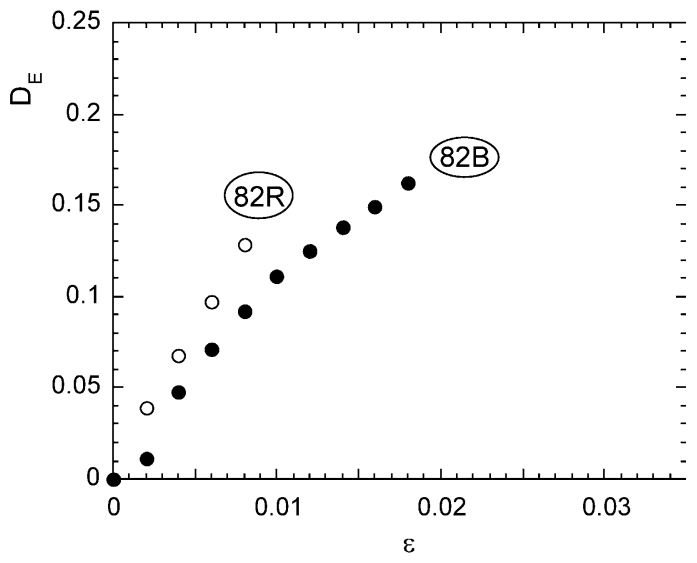

(b)

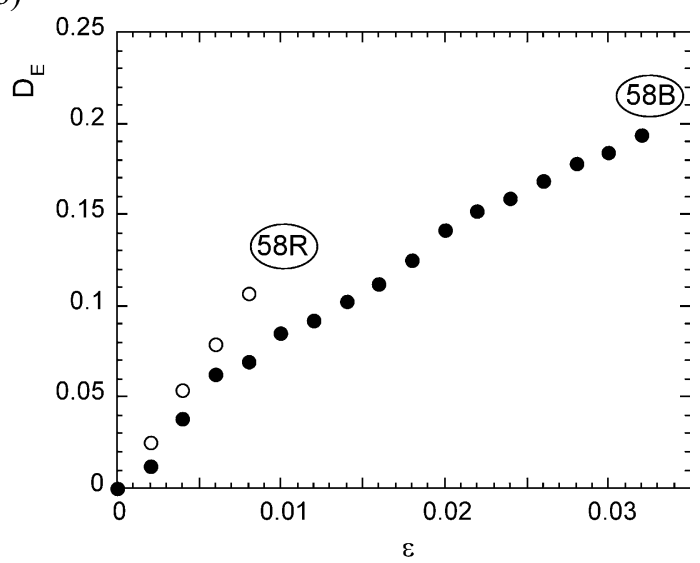

(c)

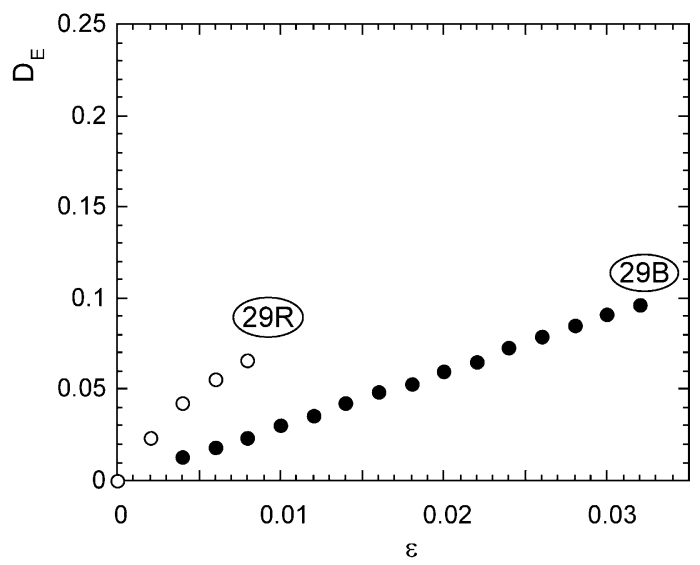

Fig. 8. Evolution of damage parameter $D_{\mathrm{E}}$ for composites (a) $82 \mathrm{~B}$ and $82 \mathrm{R}$, (b) $58 \mathrm{~B}$ and $58 \mathrm{R}$, and (c) $29 \mathrm{~B}$ and $29 \mathrm{R}$.

on the tensile flow stress of particle reinforced composites has been documented in several other studies [3034]. Smaller particles are more effective in hardening the metal matrix by dislocation punching during cool-down from processing temperatures, which accounts for the differences in yield stress [35]. At higher strains the existence of deformation gradients in the composite matrix adds yet another size-dependence to the flow stress: the smaller the reinforcements, the smaller the interparticle distances, and thus the larger the strain gradients. A large strain gradient in the composite matrix results in a greater density of geometrically necessary dislocations therein and, hence, a higher composite flow stress [36]. This size-dependent strengthening in infiltrated particle reinforced composites, including B-type composites of the present study, is treated in detail elsewhere [37].

The flow stress of the present composites is markedly dependent on reaction (Fig. 4): an increase of roughly one volume percent of reaction phase in type $R$ composites increases their flow stress relative to equivalent type B composites by about $25 \mathrm{MPa}(10-25 \%)$. Given the small volume percentage of reaction phases (Table 2) and the very low solubility of boron and carbon in aluminum, this increase in composite flow stress is most likely due to the enhancement of reinforcement contiguity with reaction (Fig. 3).

There is thus a considerable difference between elastic and plastic deformation of the present composites with respect to reaction, and hence the contiguity of the ceramic phase. The data show that interparticle ceramic bridges created by the reaction products (Fig. 3), affect load partition between the matrix and the reinforcement to a larger extent in the presence of matrix plasticity compared to the elastic regime of matrix deformation. We attribute this difference to relative particle motion during plastic deformation of these composites (particle 'rearrangement' in the context of powder deformation). Reinforcements in both composite types (B and R) have close neighbors with which they are in contact at several points (Fig. 1). Relative particle motion at these contact points, which can accommodate for plastic flow of the metal matrix during composite straining, is inhibited by bridges of reaction product linking particles together, and is hence more difficult in type $\mathrm{R}$ than in type $\mathrm{B}$ composites. Particle rearrangement is, thus, partly suppressed in type $\mathrm{R}$ composites and as a consequence straining of these composites results in a more rapid build-up of stress in the reinforcement. On the whole, this leads to an increase in the rate of strain hardening in type $\mathrm{R}$ composites as compared to type $\mathrm{B}$ composites in the low strain regime $(\varepsilon<0.005)$ (Fig. 5), and thus to an increase of the composite flow stress. The present findings are in agreement with the work of Pyzik and Beaman [4] and also with studies on interpenetrating phase composites [3,38-40].

\subsection{Damage and ductility}

Increased load transfer to the reinforcements during plastic deformation of type $\mathrm{R}$ composites is also reflected in their accelerated rate of damage accumulation compared to type B composites of equivalent particle size. This is evident in a greater loss of stiffness, 
and hence greater $D_{\mathrm{E}}$, at a given strain in type $\mathrm{R}$ as compared to type B materials (Fig. 8).

Microstructural observations reveal that the reaction products themselves are rarely broken after tensile straining. In type $\mathrm{R}$ composites, however, the fraction of broken particles is higher than in type B composites at a given strain, c.f. Section 3.3. Since stiffness loss in composites is a function of reinforcement fracture [41], the higher rate of stiffness loss in type $\mathrm{R}$ composites can be directly linked to a higher rate of $\mathrm{B}_{4} \mathrm{C}$-particle fracture; in turn, this is indicative of higher stresses in reacted particles, consistent with the discussion in Section 4.2 above. The increased rate of damage accumulation in type $\mathrm{R}$ composites is also evident in the evolution of the apparent rate of strain hardening (Fig. 5): at strains near $0.5 \%$ the strain hardening rate, $\mathrm{d} \sigma / \mathrm{d} \varepsilon$, becomes less for type $\mathrm{R}$ than for type $\mathrm{B}$ composites of equivalent reinforcement size.

Both type B and type R materials display an increase in elongation to failure as the size of their reinforcements decreases (Table 3). As above, this can be linked to the rate of damage accumulation: composites reinforced with larger particles accumulate damage at a higher rate, evident both in the evolution of $D_{\mathrm{E}}$ (an indirect measure of damage) (Fig. 8), and the direct measurement of the fraction of broken particles after tensile failure, c.f. Section 3.3. Other studies have also shown this size-dependence of reinforcement fracture in composite materials (e.g. [26,42-46]), which is consistent with a statistical failure criterion [47] commonly applied to ceramic materials [48].

The rate of damage accumulation and the ductility of the present composites can be quantitatively linked as shown in Ref. [49]. Adopting the strain-equivalence postulate of continuum damage mechanics $[50,51]$, the measured (damaging) composite flow stress, $\sigma$, can be related to the effective stress, $\tilde{\sigma}$, i.e. the stress of the same composite at the same strain but in the absence of damage, by:

$\sigma=\left(1-D_{\mathrm{E}}\right) \tilde{\sigma}$

This assumption was shown in Ref. [49] to be consistent with the behavior of similar infiltrated composites, which consist of a pure aluminum matrix reinforced with alumina particles (a system in which there is no chemical interaction between matrix and reinforcement). Plotting the effective stress $\tilde{\sigma}$ as a function of strain in logarithmic coordinates for the present composites, straight lines of slope $n=0.2( \pm$ 0.01) result (Fig. 9). In the absence of damage, thus, the present composites would display power-law hardening with a strain hardening coefficient equal to 0.2 . The same conclusion was reached for analogous alumina-aluminum composites in Ref. [49].

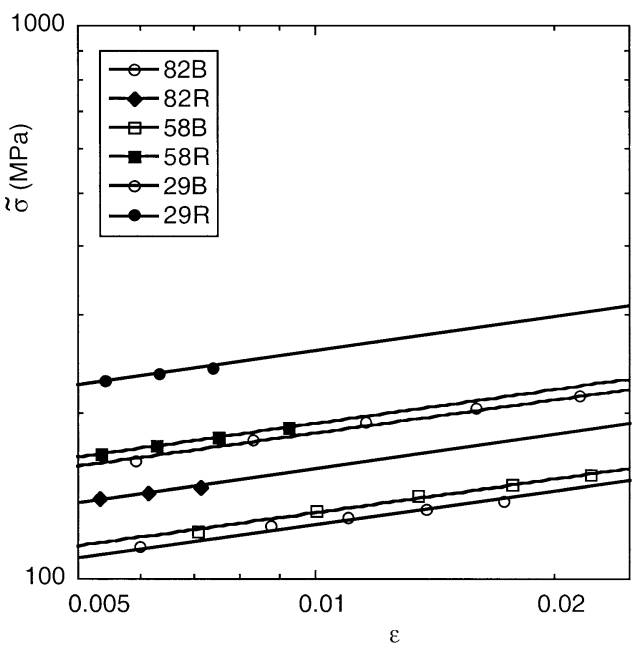

Fig. 9. Effective stress vs. strain ( $\ln -\ln$ plots) for the various $\mathrm{B}_{4} \mathrm{C}-\mathrm{Al}$ composites.

Consequently, we can write:

$\frac{\mathrm{d} \tilde{\sigma}}{\mathrm{d} \varepsilon}=\frac{n \tilde{\sigma}}{\varepsilon}$

Since damage in the present materials during tensile straining does not result in a significant increase of their volume [24], Considere's criterion may be used to link the onset of tensile instability, and hence the (uniform) elongation at failure of these composites, with the measured rate of damage accumulation. Inserting Eq. (4) and its derivative into the instability criterion, Eq. (3), and combining with Eq. (5) the composite failure strain can be expressed as

$\varepsilon_{\mathrm{f}}=\frac{n}{1-\frac{\mathrm{d}}{\mathrm{d} \varepsilon}\left[\ln \left(1-D_{\mathrm{E}}\right)\right]}$

In (Fig. 10), the failure strains of all present compo-

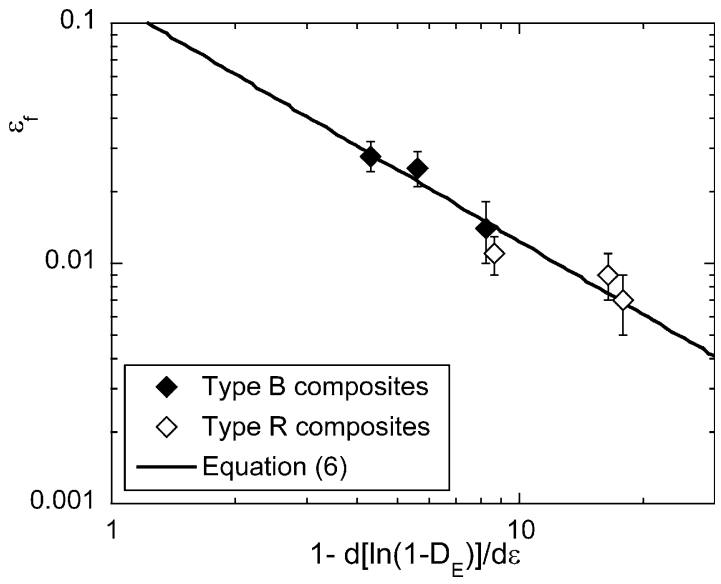

Fig. 10. Comparison between experimental data and Eq. (6) predicting failure strain as a function of the rate of damage accumulation in $\mathrm{B}_{4} \mathrm{C}-\mathrm{Al}$ composites. 
sites are plotted against Eq. (6), showing good agreement. Thus it can be concluded that the tensile fracture strain of damaging composites is primarily determined, for a given matrix and hence a given value of $n$, by the rate of damage accumulation.

\section{Conclusions}

Two reaction products, namely $\mathrm{AlB}_{2}$ and $\mathrm{Al}_{3} \mathrm{BC}$, have been identified in high volume fraction $\mathrm{B}_{4} \mathrm{C}$-reinforced aluminum composites produced by gas-pressure assisted liquid metal infiltration at $750{ }^{\circ} \mathrm{C}$. The extent of reaction increases as a function of interaction time, increasing the net volume fraction of the ceramic reinforcement in the composite, and, as a consequence, the composite Young's modulus.

Reaction also increases the contiguity of the reinforcement. This microstructural modification increases the composite flow stress indicating an increase in load transfer to the reinforcing phase during plastic deformation. While the predominant damage micromechanisms remain the same in all composites, increased contiguity results in a higher rate of particle fracture during deformation, significantly decreasing the composite tensile ductility. The ductility of the present composites is predicted by determining the rate of damage accumulation and its role on tensile instability.

The tensile properties of infiltrated $\mathrm{B}_{4} \mathrm{C}-\mathrm{Al}$ composites can thus be tailored by modifying the microstructure of the composites: (i) smaller particles result in a higher composite flow stress and elongation to failure; and (ii) increased reaction between the constituents results in a higher composite flow stress but at the expense of lower elongation to failure.

\section{Acknowledgements}

This work was funded by the Swiss National Science Foundation, projects no. 2100-049119.96 and 2055291.98. The authors wish to thank Dr Bernard Viguier for assistance with the TEM work. In addition, we thank Dr Andreas Rossoll, Dr Ludger Weber and Ali Miserez for many stimulating discussions.

\section{References}

[1] M. Gu, Y. Jin, Z. Mei, Z. Wu, R. Wu, Mater. Sci. Eng. A252 (1999) 188.

[2] R.P. Baron, C. Jones, F.E. Wawner, J.A. Wert, Mater. Sci. Eng. A259 (1999) 308.

[3] S. Schicker, T. Erny, D.E. Garcia, R. Jansen, N. Claussen, J. Eur. Ceram. Soc. 19 (1999) 2455.

[4] A.J. Pyzik, D.R. Beaman, J. Am. Ceram. Soc. 78 (1995) 305.

[5] W.C. Harrigan, Mater. Sci. Eng. A244 (1998) 75.
[6] A.D. Panasyuk, V.D. Oreshkin, V.R. Maslennikova, Sov. Powder Metall. Met. Ceram. 18 (1979) 487.

[7] T.A. Chernyshova, A.V. Rebrov, J. Less-Common Met. 117 (1986) 203.

[8] D.C. Halverson, A.J. Pyzik, I.A. Aksay, W.E. Snowden, J. Am. Ceram. Soc. 72 (1989) 775.

[9] J.C. Viala, J. Bouix, G. Gonzalez, C. Esnouf, J. Mater. Sci. 32 (1997) 4559.

[10] K.B. Lee, H.S. Sim, S.Y. Cho, H. Kwon, Mater. Sci. Eng. A302 (2001) 227.

[11] F.D. Meyer, H. Hillebrecht, J. Alloy Compd. 252 (1997) 98.

[12] H. Nayeb-Hashemi, D. Shan, Mater. Sci. Eng. A266 (1999) 8.

[13] J.J. Stephens, J.P. Lucas, F.M. Hoskings, Scripta Metall. 22 (1988) 1307.

[14] R.U. Vaidya, S.G. Song, A.K. Zurek, Philos. Mag. A 70 (1994) 819.

[15] T.G. Nieh, R.F. Karlak, Scripta Metall. 18 (1984) 25.

[16] K.T. Ramesh, G. Ravichandran, Mech. Mater. 10 (1990) 19.

[17] W.R. Blumenthal, G.T. Gray, III, T.N. Claytor, J. Mater. Sci. 29 (1994) 4567.

[18] W.R. Blumenthal, G.T. Gray, III, in: S.C. Schmidt, J.N. Johnson, L.W. Davison (Eds.), Shock Compression of Condensed Matter, Elsevier, Amsterdam, 1990, p. 393.

[19] M.T. Kiser, F.W. Zok, D.S. Wilkinson, Acta Mater. 44 (1996) 3465.

[20] A.F. Whitehouse, T.W. Clyne, Acta Metall. Mater. 41 (1993) 1701.

[21] M. Li, S. Ghosh, O. Richmond, Acta Mater. 47 (1999) 3515.

[22] S. Qin, C. Chen, G. Zhang, W. Wang, Z. Wang, Mater. Sci. Eng. A272 (1999) 363.

[23] A.R. Kennedy, S.M. Wyatt, Compos. Sci. Technol. 60 (2000) 307.

[24] M. Kouzeli, L. Weber, C. San Marchi, A. Mortensen, Acta Mater. 49 (2001) 497.

[25] D.R. Lide (Ed.), CRC Handbook of Chemistry and Physics, 73rd ed., CRC Press, Boca Raton, FL, 1992, p. 4.

[26] P.M. Singh, J.J. Lewandowski, Metall. Trans. 24A (1993) 2531.

[27] S.F. Corbin, D.S. Wilkinson, Acta Metall. Mater. 42 (1994) 1329.

[28] M. Kouzeli, L. Weber, C. San Marchi, A. Mortensen, in: T. Massard, A. Vautrin (Eds.), Proceedings of the 12th International Conference on Composite Materials (ICCM-12), Paris, France, 1999, on CD-ROM.

[29] R.M. Christensen, Mechanics of Composite Materials, WileyInterscience, New York, 1979, p. 32.

[30] P. Mummery, B. Derby, Mater. Sci. Eng. A135 (1991) 221.

[31] P.B. Prangnell, T. Downes, W.M. Stobbs, P.J. Whithers, Acta Metall. Mater. 42 (1994) 3425.

[32] R.M. Aikin, L. Christodolou, Scripta Metall. Mater. 25 (1991) 9.

[33] S.V. Kamat, A.D. Rollett, J.P. Hirth, Scripta Metall. Mater. 25 (1991) 27

[34] W.S. Miller, F.J. Humphreys, Scripta Metall. Mater. 25 (1991) 33.

[35] R.J. Arsenault, L. Wang, C.R. Feng, Acta Metall. Mater. 39 (1991) 47.

[36] N.A. Fleck, G.M. Muller, M.F. Ashby, J.W. Hutchinson, Acta Metall. Mater. 42 (1994) 475.

[37] M. Kouzeli, A. Mortensen, Acta Mater. 50 (2002) 39.

[38] D.R. Clarke, J. Am. Ceram. Soc. 75 (1992) 739.

[39] M.C. Breslin, J. Ringnalda, L. Xu, M. Fuller, J. Seeger, G.S. Daehen, T. Otani, H.L. Fraser, Mater. Sci. Eng. A195 (1995) 113.

[40] L.D. Wegner, L.J. Gibson, Int. J. Mech. Sci. 42 (2000) 925.

[41] T. Mochida, M. Taya, M. Obata, JSME Int. J. I-Solid Mech. Strength Mater. 34 (1991) 187.

[42] Y. Bréchet, J.D. Embury, S. Tao, L. Luo, Acta Metall. Mater. 39 (1991) 1781

[43] M.S. Hu, Scripta Metall. Mater. 25 (1991) 695.

[44] A. Plumtree, P. Mummery, in: A. Poursartip, K. Street (Eds.), Proceedings of the Tenth International Conference on Composite 
Materials (ICCM-10), Whistler, British Columbia, Canada, Woodhead Publishing Ltd., Cambridge, UK, 1995, p. 257.

[45] J.Y. Yang, F.W. Zok, C.G. Levi, in: P.K. Rohatgi (Ed.), Processing, Properties and Applications of Cast Metal Matrix Composites, TMS, Warrendale, PA, 1996, p. 77.

[46] J. Llorca, M. Elices, in: J.J. Lewandowski, W. Hunt (Eds.), Intrinsic and Extrinsic Fracture Mechanisms in Inorganic Composite Systems, TMS, Warrendale, PA, 1995, p. 15.

[47] W. Weibull, J. Appl. Mech. 18 (1951) 293.
[48] K. Wallin, T. Saario, K. Törrönen, Int. J. Fracture 32 (1987) 201.

[49] M. Kouzeli, L. Weber, C. San Marchi, A. Mortensen, Acta Mater. 49 (2001) 3699.

[50] J. Lemaitre, A Course on Damage Mechanics, Springer-Verlag, Berlin, 1992, p. 13.

[51] J. Lemaitre, in: F. Montheillet, F. Moussy (Eds.), Physique et Mécanique de l'Endommagement, Les Editions de Physique, Les Ulis, France, 1986, p. 88. 